\title{
Developing a Scottish Migration Monitor: a co-operative approach
}

\author{
by Alison McCleery* \& Emma Forster Department of \\ Economics, Napier University \\ Heather Ewington \& Peter Burnhill Edinburgh \\ University Data Library, University of Edinburgh
}

\begin{abstract}
This paper documents progress on setting up a Scottish Household Migration Monitor and, in so doing, traces the path of a learning curve which operated from the inception of what came to be known as the Migration and Housing Choice (Scotland) Survey through to the collection, processing, analysis and interpretation of the data it generated. Hosted by Edinburgh University Data Library, such a Monitor will be available to the academic community, and to public and private sector housing and planning agencies.
\end{abstract}

An innovative feature of the Monitor is the inclusion of information on migration motivation as well as the numbers and patterns themselves. The inclusion of such qualitative - as distinct from quantitative - data posed questions about how best to handle both data types. It is an important issue to resolve since better informed decision-making is made possible as a result of documenting and understanding the decision to migrate and how it varies in space and time. For example, urban and regional planning authorities will be able to estimate housing demand and future housing land requirements more accurately.

\section{Introduction}

The Migration and Housing Choice (Scotland) Survey was conducted in the early nineties by researchers from two Scottish Universities; Strathclyde and Napier. The purpose of the survey was to discover the intentionality, namely, the motivation behind household migration patterns, to use the data for academic research and to inform decision making by urban and regional planning agencies in both the public and private sector. We regard the work done to date as a large pilot study for what may become an ongoing Scottish Household Migration Monitor.

This paper contains descriptions of the following:

* context of the survey

* conduct of the survey

* data handling issues

* the role of Edinburgh University Data Library

* assessment of strategy and future plans

\section{Context of the survey}

Of the three components of population change, namely fertility, mortality and migration, it is migration which is the most significant, whether for facilities planners in the public sector or for market researchers in the private sector. With the decline of both fertility and mortality in recent decades, migration has become the primary process responsible for changes in population numbers and composition, with that importance magnified at the local scale (Champion, 1993). However, migration researchers may experience greater problems than researchers into fertility and mortality when they attempt to use existing data sources relating to their respective fields of study. Official data agencies release data at levels of aggregation which, on the one hand, protect confidentiality, but on the other hand, hide much migration activity. The following three diagrams illustrate how a move 'on the ground' becomes recognised as a migration only after it crosses a specified boundary, ie, is externalised.

Because the crossing of a boundary has become the defining feature of a migration, the importance of distance travelled is underplayed. For example, the moves depicted by the two horizontal arrows in Figure 1(b) would both register as migrations, regardless of their markedly different lengths. Yet the diagonal arrow in the same quadrant, although the same length as the longer of the two horizontal arrows, would not count as a migration at all, even although it is more than twice the length of the shorter horizontal arrow. Only at the level of disaggregation shown in Figure 1(c) does the long diagonal arrow register as a migration. However, even at this level the two short-distance moves in the bottom left quadrant do not count as migrations. Thus, not only is some migration information concealed altogether, but also distance information is lost, which is 
significant because short-distance moves indicating residential mobility are more important numerically than long-distance migration and further, that the motivation behind each type of move is different.

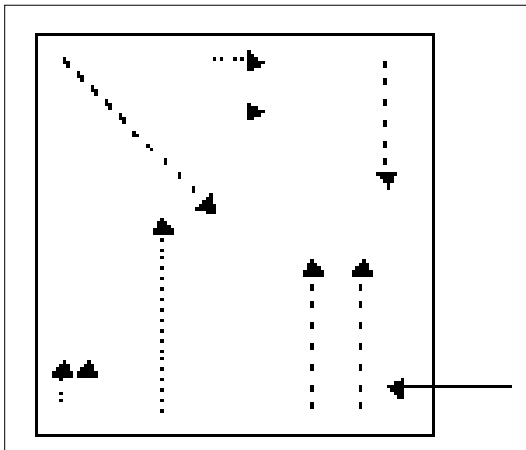

Figure $1 \quad$ (a) 1 registered migration

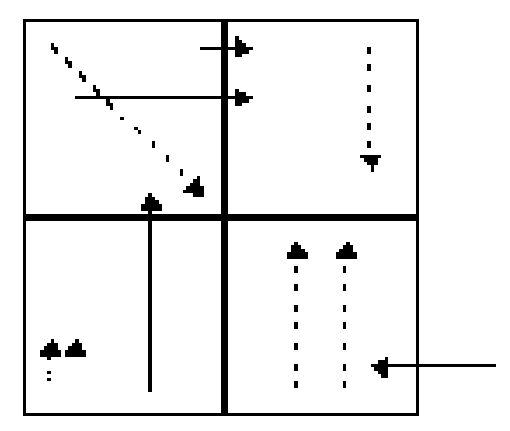

(b) $1+3$ migrations

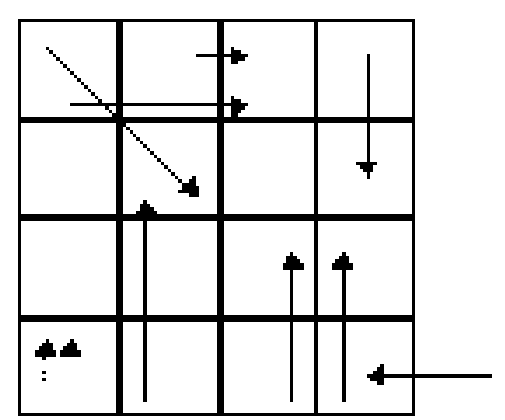

(c) $1+3+4$ migrations

The solution suggested by Forbes and McCleery (1991) is, in an ideal world, to attach a specific geographic reference to the data at the point of collection which would then permit analysis of all moves and provide the flexibility to aggregate the data to whatever level, with due regard to confidentiality.

Migration researchers in Scotland are more fortunate than most in having access to the Register of Sasines ${ }^{\mathbf{1}}$ The Sasines Register is a land register, unique to Scotland, which records every private property transaction and therefore allows every moving household in the private sector to be identified. The information contained in each record is the name and address of the owner of the present property, a previous address (of questionable accuracy - see below) and the price of the sale. Used judiciously, the Register of Sasines provides a reasonably accurate record of the origin and destination of moving households by precise postal address. Tracking of movements is theoretically possible at the lowest geographic level, namely the household. However, in practice, although the present address is accurate because it is recorded from legal documents relating to the sale of that property, the previous address information is collected mainly for administrative reasons. It may refer to the previous long-term address, but equally could refer to temporary accommodation occupied prior to the move or might even be the new address if there was a delay in completing the legal documentation. As McCleery (1980) emphasises, as a source of migration data, the Register of Sasines has to be used with care.

Furthermore, even if it is possible to produce accurate patterns of moves on the map, it should be recognised that these are merely the visible trace of an invisible, complex, increasingly segmented and largely unexplored household decision. It is the accumulated decisions of all the moving households which drive the migration streams. Without some knowledge of these decision processes, and how they may vary from place to place, from time to time, and from household to household, it is impossible to estimate future volumes and directions of moves. Thus is introduced an unknown factor in estimates of housing demand, and consequently housing land requirements are difficult to assess.

Although to date, some research has been carried out investigating movers in Scotland (Garner, 1980; Forbes, 1989), there has yet to be a comprehensive survey of all tenures at the national level. Forbes' paper examined migration patterns in Scotland's largest city, Glasgow, but was more innovative than either descriptive or analytical in that it used pre-existing data to explore the feasibility of an experimental Migration Monitor. Now this present paper reports on the broadening of the initial work into this area. In so doing, it traces the path of a learning curve which operated from the inception of what came to be know as the Migration and Housing (Scotland) Survey through to the collection, processing, analysis and interpretation of the data it generated.

\section{Conduct of the Survey}

The survey's two principal investigators were Jean Forbes of the Centre for Planning at Strathclyde University in Glasgow and Alison McCleery of the Department of Social Sciences at Napier University in Edinburgh. Building on her previous work, the current project was initially designed by Forbes to explore the various elements in the decision to move within the West of Scotland. The subsequent involvement of McCleery allowed coverage to be extended to include the whole of mainland Scotland. The Data Library, located at the neighbouring University of Edinburgh, was brought in at a later stage to introduce a greater element of economy and efficiency to the questionnaire design and subsequent data processing. 
The survey data was gathered by means of a postal questionnaire mailed to a $25 \%$ sample of households having moved between January and October 1990, identified from a computerised version of the Sasines Register held by the Land Value Information Unit at a fourth Scottish University, Paisley University. The unit is is a commercial concern and deals with requests for data from organisations such as chartered surveyors, builders, local authorities and researchers. Computerised housing sales records for the whole of Scotland are available from 1989 onwards and, for some parts of the country, from 1979.

Mailing of the questionnaire was made possible with the co-operation of a number of local government planning departments ${ }^{2}$ whom the investigators had succeeded in interesting in the project. The Royal Mail (Post Office) also helped because they had recognised that the survey would collect useful information about public awareness of the postcode ${ }^{3}$; the questionnaire asked respondents to provide both their previous and present postcodes.

The design of the questionnaire was informed in two ways; firstly, it was influenced by the elements in an $a$ priori model of the process of decision-making developed by Forbes (1989) and secondly by elements related to housing supply and local environmental quality proposed by the collaborating planning departments. In essence, the questions were divided into 4 types:

1. question initiating open-ended answer as text where was your previous house?

2. question with pre-defined answer categories, only one answer per question what type of house? Detached [ ] Semi-detached [] Terraced [] Flat* [ ] *Apartment

3. variation on the above, essentially one question, but with each possible factor presented as a separate question with only one answer per question, either yes or no what factors influenced your decision to move? job transfer [ ]

4. question inviting multiple, open-ended answers as text which other localities did you consider?

During the course of the project, the questionnaire was enhanced as a result of further consultation with the planning authorities from whom we sought help with distribution of the questionnaires. Variations between versions were minor, consisting mainly of additional questions, e.g. including a question about car ownership and a modification allowing respondents to specify other reasons for leaving the previous house and choosing the present house, other than the pre-defined reasons given on the questionnaire. The inclusion of the latter option allowed respondents to provide information in their own words about their motivation for moving. The challenge later was how best to translate these subjective snippets of information into objective data. Apart from these additions, consistency was maintained to allow comparability of the core questions.

As expected with a postal survey, the overall response rate fell short of 50\%, although this varied decidedly from District to District. The resultant 10,006 cases represented about 1 in 10 of all private sector residential movers for the period. A proportion of Strathclyde respondents volunteering their telephone numbers was also followed up with a more detailed survey of search patterns.

\section{Data handling issues and the role of Edinburgh University Data Library}

\section{Data collection}

The survey data were collected and processed at different times by different institutions. A pilot study was conducted first on one area of Strathclyde Region, the sprawling, industrial city of Glasgow. The second, and larger survey covered six Regions; the rest of Strathclyde, Dumfries and Galloway, Fife, Grampian, Tayside and Central. Forbes at Strathclyde University organised data collection for both surveys and because of the large number of replies, considered it cost-effective to use an outside bureau agency to process the data. The two Regions of Fife and Highland, took on responsibility for collecting and converting their own data and, with assistance from EUDL, McCleery collected and processed data from the 
remaining two Regions, Lothian and Borders.

The smaller number of the East coast replies, together with financial constraints, prompted the investigation of an in-house solution to processing the data. The advantage of this approach was that we gained greater control over the data, but we still had to ensure that it was in a format consistent with the bureau-processed data which, because handled first, was regarded initially as the standard to follow. The West coast data had been converted into rectangular numeric data files and processed as SPSS system files. Although Strathclyde University operate a VAX system and Edinburgh and Napier Universities operate UNIX, we did not envisage any problems with data transfer between the two systems.

\section{In-house processing}

On advice from EUDL, it was decided to use the database package FileMaker Pro to input and store the East coast results. EUDL had used the software successfully on a number of other projects and thus was able to confirm its suitability for the purpose. In particular, it was a user-friendly package which a new keyboard operator could quickly learn how to use. The following positive attributes apply:

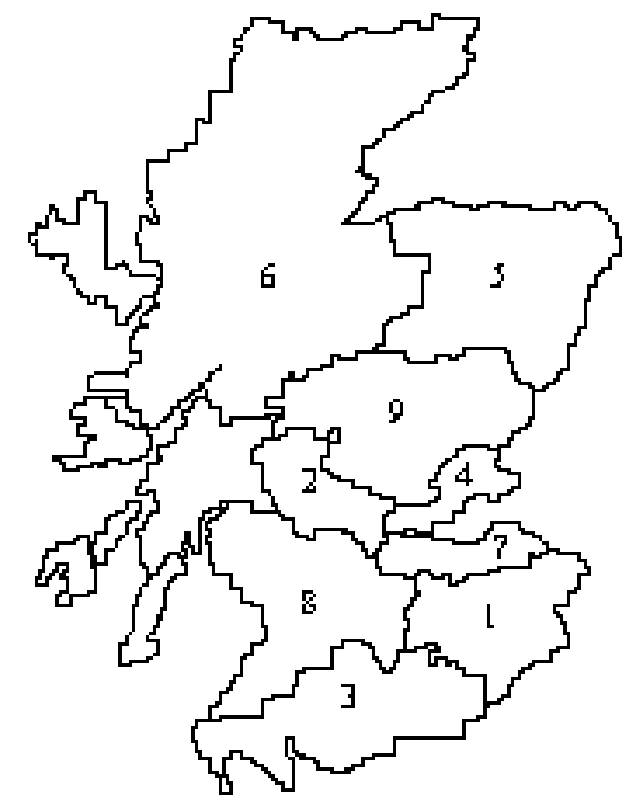

Figure 2: The administrative map of mainland Scotland

\section{Key to Regions}

$\begin{array}{ll}1 & \text { Borders } \\ 2 & \text { Central } \\ 3 & \text { Dumfries and Galloway } \\ 4 & \text { Fife } \\ 5 & \text { Grampian } \\ 6 & \text { Highland } \\ 7 & \text { Lothian } \\ 8 & \text { Strathclyde } \\ 9 & \text { Tayside }\end{array}$

* database definition is simple

* the facility to construct different views of the database (layouts) allowed the construction of a data input screen which closely resembled the layout of the questionnaire - we reckoned that the similarity between the questionnaire and input screen would reduce the number of input errors

* field display options such as checkboxes, radio buttons, pop-up menus and pre-defined lists helped the operator to input the data efficiently

* the lookup facility enabled automatic coding of some data items - additional fields were created for each question requiring either a yes or no answer and the fields automatically filled with 0 s and 1 s depending on whether or not the checkbox was clicked

* data validation mechanisms ensured that no invalid answers were input (e.g. text replies instead of numeric) and that no questionnaire could be entered into the database twice

* the export facility provided output usable with SPSS. Unlike the bureau processed data, we exported tabseparated output files and created free as opposed to fixed data format SPSS files, thus allowing us to store variable length data items, such as the postcode

\section{Assessment of strategy}

Overall, FileMaker Pro matched expectations. Inputting data was relatively trouble-free and early results were obtained from the database prior to input and analysis within SPSS. It was useful to have these results to compare with the SPSS results to ensure that the data had transferred correctly between environments. Also, we were able to input all data from the questionnaires into the FileMaker Pro database, both numeric and textual, whereas not all items from the West's replies had been converted into machine-readable form. 
Specifically, postcode information had not been transcribed. Although this information could still be retrieved from the questionnaires, it would be a time-consuming exercise and perhaps now, as the survey data ages, considered not worth the effort. EUDL recommended that the postcode be recorded in our data because many official statistics are postcoded, including the Population Census, and thus the code would provide the link with other important datasets. The last Census for the UK was carried out in 1991, shortly after our survey was conducted, and so we were keen to compare our results with those of the Census.

Also, there is no machine-readable version of the exact text of the answers to the open-ended questions. A coding scheme for these answers had been devised and applied to the West's data, but when it came to using it to code the East coast replies, we felt that a more detailed schema was required. And so we enhanced the original coding and applied it to our data. This has mean't that some of the data has a more detailed level of classification for these variables and again, only by returning to the West's questionnaires would be able to standardise the treatment of this data item.

In sum, we think that we benefitted by building the Filemaker Pro database; we were able to stagger handling of the data, processing the less problematic data items first, producing some results and returning to the more difficult items (such as the open-ended questions) as and when time and resources permitted.

\section{The spatial element}

A fundamental, and what has proved to be an on-going operation has been processing the survey's spatial data items; ie, the locality of previous and present houses, location of places of work and other areas searched. We wanted to attach a National $\mathrm{Grid}^{4}$ reference to each of these items and be able to calculate, for example, the distance moved from previous to present house, how far respondents travel to work and the extent of their search area. Also, with grid referenced data we would be able to use GIS technology (e.g MapInfo) and plot migration movements. The planners in particular had expressed interest in maps of our findings.

However, for the purposes of this study it was decided not to record the address data from the Sasines records. Instead, having used the Sasines successfully to identify the migrating households, we included questions in the questionnaire asking in which locality the respondent previously and presently lived. At the time, there were cogent reasons for this course of action. Firstly, at the start of the pilot project, the team was not aware of an easy and quick way of grid referencing the precise postal address. Secondly, there was the problem of potential inaccuracy of the previous address recorded in the Sasines record. And thirdly, in this particular migration project, sensitive motivational migration information might not be revealed by respondents nervous in the knowledge that it was attached to their actual postal address. In retrospect, this decision was a mistake. If the survey were being repeated, we would pay more attention to the geographic detail and fully exploit the resources of the Sasines, trying to overcome the confidentiality issue in a different way.

Despite the shortcomings of our spatial data it still had to be processed. Although the first batch of replies was grid referenced using printed information sources, with the subsequent involvement of the Data Library, we learned that online grid referencing facilities were available which not only would automate a laborious task, but also provide sufficient geographic detail to produce meaningful maps.

We used the following Data Library utilities to grid reference our data:

\section{* Postzon File}

The Postzon File provides 12 digit grid references to 10 metre resolution. The file is extracted from a Central Postcode Directory maintained by the Post Office and contributed to by a number of official organisations such as the Office of Population, Censuses and Surveys, the General Register Office (Scotland) and the Welsh Office. In addition to grid references, it contains information about postcodes (date of termination of a postcode) and area and country codes.

\section{* Index of Placenames (IPN)}

Both datasets can be used interactively and in batch mode; the latter was the appropriate method for our application. A FileMaker export file was produced consisting of, where it existed, the postcode and placename information for each reply, together with each reply's unique reference number. The more specific match was on the postcode and so we used the Postzon file first and only if unsuccessful, tried to match the placename using the IPN. Both methods however were an improvement on a grid reference obtained from the printed sources in terms of speed of processing and the accuracy of the grid reference. 


\title{
Data Linkage - methodological concerns
}

The original decision not to record postcode information in the data from the first two surveys was taken partly because of an initial lack of awareness of its use to link with other datasets. It also related to doubts about its use in deriving a geographic reference; in particular, there was concern about the method by which a grid reference is allocated to a postcode. The practice of the General Register Office (Scotland) has been to allocate the reference to the nearest 10 metres of the centre of the building judged by eye on the map to be the centroid of the area covered by the postcode.

As Forbes and McCleery (1991) have argued, postcode units vary widely in size and shape between different parts of the country. They are smallest in urban areas, but in sparsely populated Highland Scotland, they are large and straggling, and thus the process of allocating a centroid is a nonsense; subsequently to attach a 12 grid figure reference "lends spurious accuracy to a technique which is at the very least unsophisticated". It could be that the effects are marginal. But a more pessimistic view cannot be dismissed:

\begin{abstract}
Massive amounts of public money have been directed in recent years to areas of social and/or economic 'need', such areas being defined by mapped patterns of aggregated data. Yet the need may not exist where the map says it does, and the map may fail entirely to reveal a need locality which does exist
\end{abstract}

Forbes and McCleery (1991)

This draws attention to problems of spatial comparability. In addition there is also arguably a problem of comparability through time since the Royal Mail allocates and re-allocates postcodes as the built environment evolves, that is, as buildings appear and disappear. Despite these acknowledged failings, the postcode is, as explained above, currently the best tool there is for achieving data linkage.

\section{Data Linkage - practical applications}

As things turned out we had an earlier occasion to use the linkage facility; namely, to overcome the problem of the East's unavoidably small sample. We had hoped to issue statistics for specific places, but in many cases the number of replies was too few to draw any meaningful conclusions and we were also wary of breaching confidentiality.

Although, all replies had been labelled by their District and Regional identifier, we considered that statistics produced for these large and heterogeneous areas would be not very meaningful. Fortunately, suitable sub-areas were identified by the planners using their local knowledge. They identified Community Council Areas (CCAs) which were largely homogeneous in terms of socio-economic composition and also constituted possible housing market areas. The CCAs had been defined in terms of the geographic areas used to release the Population Census data, namely the Census Output Areas, which in turn comprise one or more unit postcodes. Our task therefore was to discover in which CCA each reply was located. If we had had accurately grid referenced replies and if the CCAs been available in digitised form, then the task could easily have been performed using the GIS technique, 'point-in-polygon'. However, we were not in this fortunate position and so we had to rely on another of the Data Library's data services, UKBORDERS.

UKBORDERS is a national, online service providing digitised boundary data for standard and user-defined areas based on the geography of the Population Census. By combining data from UKBORDERS and information from the planners on the composition of the CCAs, we were able to construct a lookup table detailing the CCA and Census Output Area for every postcode unit. The final step was to match the replies against this file and create two new variables of CCA and Census Output Area. We then re-released the earlier statistics produced for the newly-created areas.

\section{Overview}

A project which started life as a rather modest example of legitimate, but by nature organic, academic enquiry in the best tradition of the ancient Scottish universities, had slowly but surely changed into a monster. It was not so much Nessie as messy! This situation arose mainly from the project's funding arrangements. In short, there were no funds available at the start of the project and it was able to progress only because of personal investment by Forbes who financed a small-scale, pilot study on Glasgow, with the hope that the rest of the country could be surveyed in time as and when funds became available.

It was fortunate that we were able to interest a number of organisations outwith the academic community in the project, who agreed to contribute either financial assistance or help in kind, e.g. posting the questionnaires. However, in return, we were obliged to consult with them about the content of the questionnaire and to provide them with basic results. The effect of having multiple contributors was both positive and negative: positive insofar as the survey would never have been carried out 
without their help, negative in that control of the project became dispersed, with the danger that the initial objectives of the survey would be lost as we tried to be all things to all men.

It was unfortunate that EUDL was not involved at the start of the project. Their assistance with questionnaire design, data input and processing was important and much appreciated but, because of circumstances, consisted mainly of rectifying errors that might have been avoided if there had been better-informed planning at the start. Ideally, their input should have been sought at the beginning, a project plan developed and adhered to throughout the project. However, we do regard the survey as a success and are currently collaborating to produce a national dataset to be deposited with EUDL and thus be available for use by other researchers.

\section{Dissemination through the Internet}

EUDL has also drawn attention to the potential use of the Internet and the World Wide Web for both publicising the data and possibly providing access. We have created a few pages about the survey and have added them to the Data Library's World Wide Web server, datalib. Also, we have produced a WAIS (Wide Area Information Server) index of records about the survey questions, including details of variable and value labels, whether or not the variable exists for a particular area and how it was processed or derived. The organic growth of the dataset had given us the problem of where to record details of its changing structure, but fortunately, the Web arrived during the course of the project and offered us a possible solution to the documentation problem.

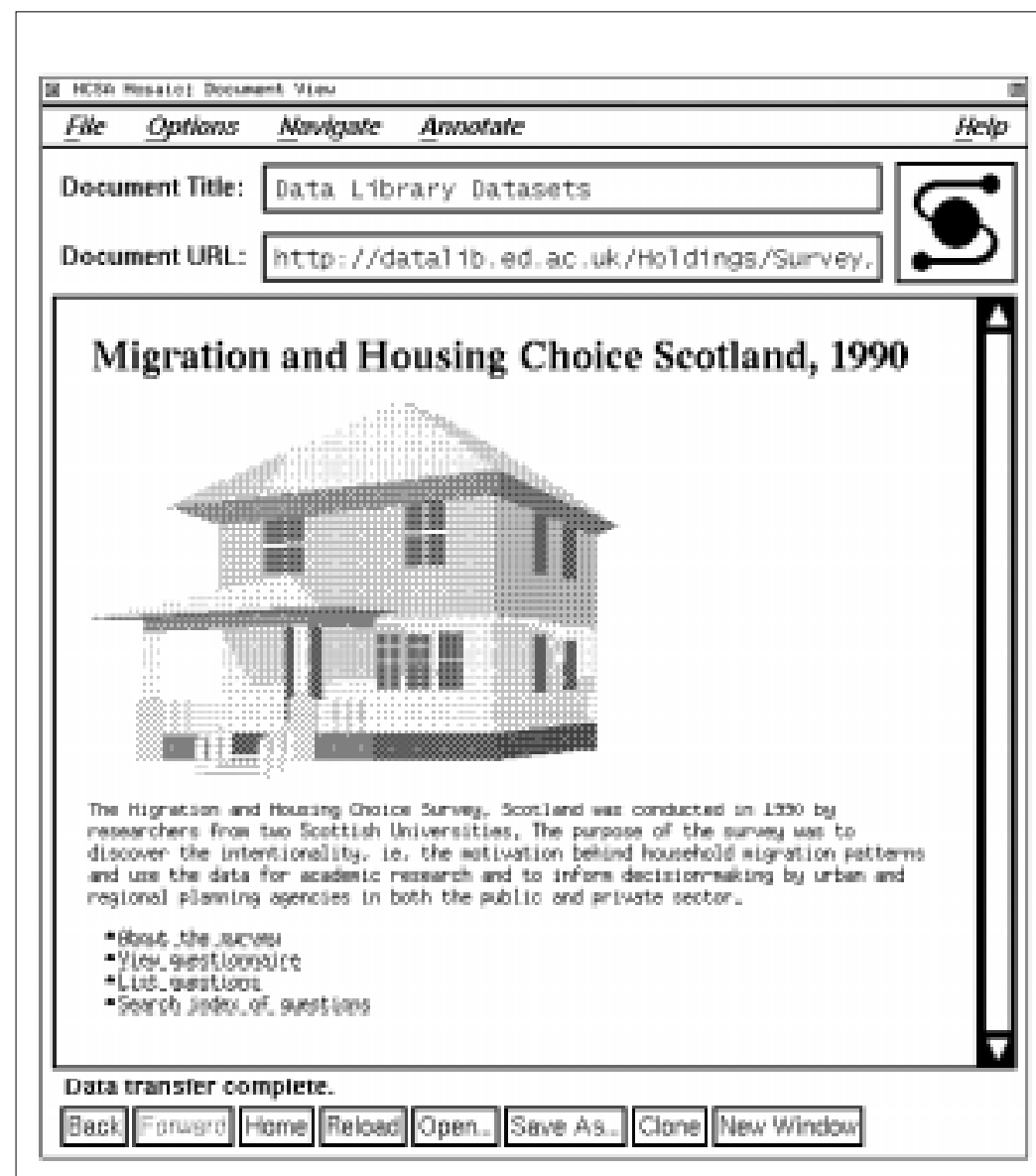

Figure 3: home page

The home page reproduced here lists the four main menu options:
* About the survey
* View the questionnaire
* List questions
* Search index of questions

We thought it useful to let potential users view the questionnaire as an aid to helping them decide whether or not the data would be of value to them. We created created a gif image of the questionnaire using EUDL's scanning facilities. EUDL is involved in a number of projects involving scanning. Currently they are working with the University Library to offer Internet access to part of the Library's Special Collections by creating an index to scanned images of catalogue records. They are using a flatbed scanner controlled by the Optical Character Reading (OCR) software FormFile.

We have created a WAIS index of information about the survey variables using the indexing software, freeWAIS. Users are prompted to search the index by keywords. Additionally, they can view a question list in which each entry is a hypertext link to the appropriate index record.

In addition to the above information, we are also investigating using the Web to access the data itself directly and produce basic statistics for standard areas. We have noted other attempts to do this, including by the University of British Columbia and Statistics Canada. However, we realise that direct access to our data may require to be limited because of the confidentiality issue. For experimental purposes we intend to hardwire into the system, a selection of counts for the larger geographical areas.

\section{Conclusion}

Although subject specialists provided the 
initial stimulus for this investigation and are predominantly involved in the interpretation and exploitation of results, they did not have the information-handling skills or resources necessary to create the dataset from which the results would be derived. The involvement of data management specialists, Edinburgh University Data Library, was therefore an important factor in the successful conduct of this project.

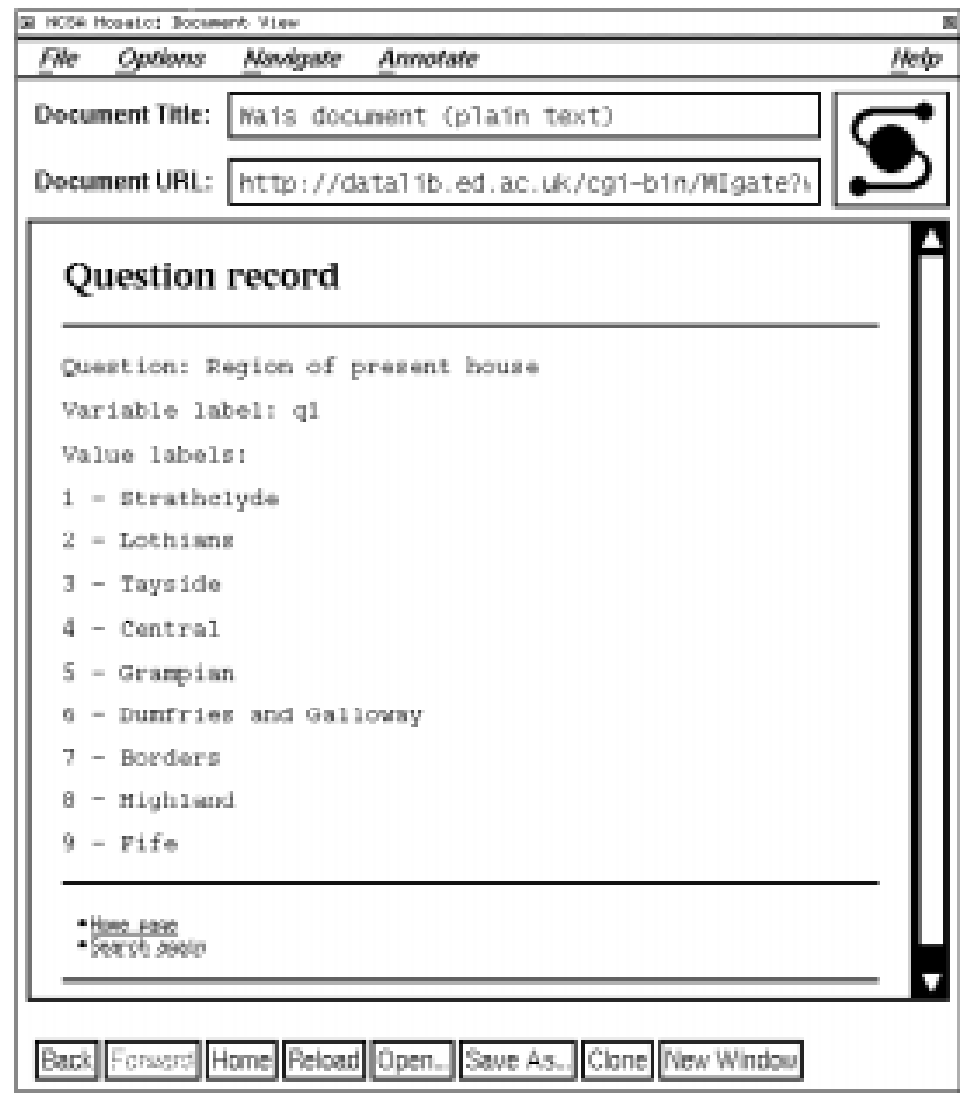

Figure 4: index of questions
Despite the many flaws, results have been produced which have indicated potential further lines of enquiry. Also, the nonacademic organisations who were initially involved have reacted well to our findings. Furthermore, having been approached by a number of private sector organisations such as house builders and the government housing agency, Scottish Homes, we now feel confident in our ability to convince a consortium of these bodies to put together the funding for a comprehensive and efficiently organised Migration Monitor. During the course of the survey, vital lessons have been learned for the future. Should the survey be repeated in a more favourable funding environment attention should be paid to the following issues:

\section{Organisational}

* of paramount importance is the need to agree at the outset what the survey is about; then to ask questions which elicit the correct answers, that is, answers which provide useful information

\section{Methodological}

* we have highlighted the issue of spatial referencing, that is, problems associated with the use of the postcode as the UK standard. Frustrating though the postcode may be, nevertheless, by a process of historical accident, it has become firmly embedded in the data processing activities of UK official data collection agencies

Finally, two issues; one specific, the other more general arising from the foregoing discussion. Firstly, the present investigators have restricted the use of the data generated to supporting the activities of the organisations which contributed funding to the project. However, with the deposit of the dataset with the Data Library, the data will become more widely available and used by researchers who may potentially adopt a more challenging attitude. For example, the widely accepted use of the housing market area (such as the CCA supplied to us by the planners), could well be rejected. We have become aware that we might have been too much in the pocket of the planners. However, this is a dilemma faced by many in the UK with the shift during the 1980s from publicly-funded academic research to commercially-sponsored consultancy work. The question we may need to ask is this: what will happen if, with the wider release of the data, other users end up biting the hand that fed us!

Secondly, there may be a fundamental mismatch between the perspective of data professionals and the nature of academic enquiry. The former is rational, organised and has to adopt a pragmatic, problem-solving approach. The latter is organic and incremental, with a tendency to go off at tangents, some of which open up new and fruitful avenues of enquiry. For example, as we analysed the respondents own answers about why they moved house, the issue of health arose frequently; an option not given as one of the multiple-choice answers. 
Issues of this type point to one of the many benefits of an organisation such as IASSIST: it serves as a forum where data professionals meet to consider all aspects of the data provider/user interface and where subject specialists are welcome to learn from and contribute to the discussions.

\title{
Appendix
}

\begin{abstract}
Migration and Housing Choice (Scotland) Survey: some key results
These testify to the increasing complexity of motivation for migration. In other words people are citing more and different reasons for their move than previously. Respondents gave a mean of 1.48 reasons for leaving their previous address, but 2.64 reasons for choosing their new one. While this confirms the operation of a trigger for leaving the old home, it also suggests that at the level of choosing, the decision is based on multiple factors. Furthermore, it is apparent that a hard and fast distinction between pushes and pulls (i.e. from the origin or to the destination) is no longer entirely valid. For example, in response to a partner's complaints that the present home is too cramped, a person may seek promotion at work and be moved to a branch manager's position in a distant location. Was the household pushed, pulled, or a bit of both?
\end{abstract}

Perhaps this is not a particularly well-chosen example, however, since another key finding relates to the declining significance of employment as a motivational factor relative to quality-of-life considerations. While short-distance moves have never traditionally been predominantly job-related (as might be expected), now, apparently, this is increasingly the case also with long-distance moves. This is only partly explained by the increase in retirement-related moves associated with the changing age structure in the UK and the Western world universally. It also seems to reflect a change in the balance of importance between macro-structural and micro-behavioural determinants of - or more properly influences upon - migration. Increasing segmentation of markets for goods and services mirrors precisely the growing profusion of life choices and chances. The consequent diversification in 'lifestyle' is itself associated with an almost complete disintegration of any remaining correlation with household income.

So it is that classifications such as 'the elderly', 'the average family', 'single-person households' or even 'multi-adult households' are increasingly superficial and meaningless. Elderly people may be active, semi-independent or dependent; they may be young elderly, elderly or very elderly; they may live alone - whether as a result of being never-married or widowed - or with a spouse, sibling, offspring or companion. Their incomes, tastes and aspirations within each sub-group may vary in as many ways and more. A print-out of comprehensive cross-tabulations for the elderly group alone would make serious inroads into British Columbia's forests!

Yet for all that people attempt to carve out a very specific spatial and social niche for themselves according to their particular circumstances, there exist certain quality of life variables which, taken together, identify a highly desirable local environment which, other things being equal, most people would seek after - for Europeans perhaps to live in Geneva, for Canadians, Vancouver? Nor is it even necessary to compromise on lifestyle choices for the sake of a high quality-of-life, if the two are pursued at different scales. Measurement of quality-of-life is, as suggested above, appropriate at the level of inter-urban comparison; satisfying individual lifestyle requirements is carried out at the intra-urban level. Yet the two cannot be completely divorced from each other as the following example perhaps indicates.

In the Glasgow University quality-of-life ranking of the thirty-eight largest cities in Britain, Edinburgh came out top. In our survey fewer of the respondents moving either within or to Glasgow cited liking the local environment as a reason for choosing their house than was the case in Edinburgh (56\% to 64\%). Evidently longstanding rivalry which has traditionally existed between Glasgow and Edinburgh is not yet dead, and the perception of Glasgow as a declining industrial city with problems of urban decay and deprivation persists. Edinburgh, by contrast, is associated with the successful financial services industry and with fine architecture and gracious parks. Moreover, our survey found that it is precisely these types of quality of life attributes which seem to be accorded higher significance by many working people than proximity to their place of employment, the latter for the present being considered a stretchable link.

Some interesting relationships also emerged between house price and distance moved and between housing density and distance moved. A higher proportion of those moving into the most expensive properties moved either longer distances or intermediate distances. This could be interpreted as a sequential process of initially a coarse-grain employment-led interregional move and later a fine-grain environment-led intra-regional move. The latter is less constrained by the requirement to be close to work and therefore permits a wider search area and a longer move locally than in the case of the lower paid who cannot afford the cost of commuting. This speculation is supported by the finding that a lower proportion of households migrating intermediate distances mentioned convenience to work as an influence upon their choice of destination. 
Finally, it was not surprising to find that in urban areas the typical move is very short, although this is offset by a small proportion of very long extra-area moves. Less well appreciated is the opposite situation in rural areas, where the typical intra-regional move is longer, presumably because of the longer distances between localities offering a comparable level of housing choice. Thus, in the very rural district of Argyll, 62\% of movers have travelled 30kms or more, as against $18 \%$ for Glasgow, Scotland's urban heartland. The short distance move figures are the reverse, with $29 \%$ for Argyll and 54\% for Glasgow.

It would be possible to produce a PhD on the interpretation of the results from the Housing Choice (Scotland) Survey. Indeed this is precisely what one of the authors of this paper, Emma Forster, is currently undertaking. In so doing, she is transforming herself into that still rare breed of highly-skilled and highly-prized individual who is both a knowledgeable subject specialist and a competent data manager.

* Paper presented at IASSIST95 May 1995 Quebec City, Quebec, Canada.

\section{Bibliography}

Champion, T. (1993). 'Introduction' in T. Champion (ed.). Population Matters: the local dimension. London : Paul Chapman Publishing Ltd, pp. 1-21.

CANSIM data base: Canadian socio-economic information management system [computer data]. Ottawa, Ont.: Statistics Canada [producer and distributor], [19-]. 1 data file and accompanying documentation. http://www.datalib.ubc.ca

CITIBASE, Fame Economic Database 1946- [computer file]. New York : FAME, 1978-1994. http://www.datalib.ubc.ca

Datalib: Edinburgh University Data Library’s WWW server [computer data]. Edinburgh: Data Library, University of Edinburgh, 1995- http://datalib.ed.ac.uk

FileMaker Pro [computer file]. FileMaker Pro 2.Obv2, May 1993. Computer program. Santa Clara, California : Claris Corporation. Copyright 1988-1993 Claris Corporation.

Forbes, J. (1989). 'Migration Monitoring and Strategic Planning', in P. Congdon \& P. Batey (eds.). Advances in Regional Demography. London \& New York : Belhaven Press, pp. 41-57.

Forbes, J. \& McCleery, A. (1991). The 1991 Census: spatial referencing considerations. ESRC Regional Research Laboratory for Scotland Working Paper No. 21. Edinburgh: ESRC RRL Scotland, 1991.

FormFile [computer file]. Version 1.11. Livingston, Edinburgh : Seel Ltd, 1994.

freeWAIS-1.0-sf [computer file]. Release 1.0 2/16/93. Thinking Machines, Jim Fullton, Kevin Gamiel, Jane Smith, Tung Huynh, Ulrich Pfeifer.

Garner, C.L. (1980). Residential Mobility in the Local Authority Housing Sector in Edinburgh 1963-73, Unpublished PhD Thesis, University of Edinburgh.

IPN [computer file]. Computer program. Edinburgh : Edinburgh University Data Library, 1991.

MapInfo [computer file]. MapInfo Version 3.0.2. Troy, NY : MapInfo Corporation. Copyright 1985-1994 MapInfo Corporation.

McCleery, A. (1980). The Register of Sasines as a Source of Migration Data, British Urban and Regional Information Systems Association Newsletter 46: 16-17.

Postzon [computer file]. Edinburgh : Edinburgh University Data Library, 1991.

Rogerson, R. Findlay, A, Morris, A, Paddison, R. August (1989). In Cities. Variations in quality of life in urban Britain. pp. 227-233.

The Scottish National Dictionary. Edited by William Grant and David D. Murison. Edinburgh : The Scottish National 
Dictionary Association Limited, 1952.

UKBORDERS: ESRC national online service for the extraction of digital boundary data [computer data]. Data Library, University of Edinburgh. http://borders.ed.ac.uk

\section{Notes}

1. Sasines is an old Scottish word meaning the act or procedure of giving possession of feudal property, until 1845 by the symbolical delivery of earth and stone on the property itself. Symbolic delivery has now been abolished and all Sasines are registered in the Register of Sasines which is now being converted into a computerised Land Registry.

2. At present, Scotland's local government administration is divided into two tiers; one level of 9 Regions and a second level of 56 Districts and 3 Islands Areas. Planning responsibilities are shared between Region and District, the former involved in strategic planning issues, the latter in development control matters. However, by the end of 1995, this two-tier arrangement will be replaced by one level consisting of 32 unitary authorities.

3. The primary purpose of the postcode is to assist the Post Office to deliver mail. The postcode is a combination of between five and seven letters and numbers which define four different levels of geographic unit; the Postcode Area (120 in the UK), the Postcode District $(2,700)$, the Postcode Sector $(8,900)$ and the Postcode Unit $(1.5$ million).

4. The National Grid is a reference system of squares overprinted on all Ordnance Survey maps since the 1940s. The system of breaking the country down into squares allows any place in the country to be given a unique reference code.

5. Crofting is a system of land tenure. A croft is a smallholding worked by a tenant, comprising a plot of arable land attached to a house and a right of pastorage in common with others. The sale of crofts has traditionally been governed by Crofting Law which restricted free sale. The Western Isles and Orkney and Shetland were not included in the survey because of complications associated with the unique form of housing tenure called crofting which is peculiar to these areas and which distorts the housing market there. 